\title{
Comparative Modeling of HSF Constructed Wetland Performance With and Without Evapotranspiration and Rainfall
}

\author{
Konstantinos A. Liolios • Konstantinos N. Moutsopoulos • \\ Vassilios A. Tsihrintzis
}

Received: 11 November 2013 / Accepted: 15 January 2014 / Published online: 6 May 2014

(C) Springer International Publishing Switzerland 2014

\begin{abstract}
The effects of meteorological parameters, i.e., evapotranspiration (ET) and rainfall (P), on the flow and BOD fate in horizontal subsurface flow constructed wetlands (HSF CW) are presented based on numerical simulation, using the Visual MODFLOW-MT3DMS code, which is based on the finite difference method. This model was used to simulate five HSF CW pilot-scale units, which were constructed and operated in the Laboratory of Ecological Engineering and Technology. Experimental data from these facilities were used to calibrate and verify the numerical procedure. ET was estimated based on a previous study proposing the use of the Blaney-Criddle method, and was introduced in the model. For a characteristic time period, rainfall values from observed events were also entered in the model. The model was then used to test effects of ET and rainfall on effluent concentration under various conditions, showing a more intense effect of ET and a less significant effect of rainfall. It was also used in test runs comparing the performance, without and with ET, under various vegetation, porous media size, HRT and temperature conditions.
\end{abstract}

Keywords Constructed wetlands · Horizontal subsurface flow · Evapotranspiration · Rainfall • Modeling $\cdot$ MODFLOW

\footnotetext{
K. A. Liolios $(\bowtie) \cdot K$. N. Moutsopoulos

Laboratory of Ecological Engineering and Technology, Department of Environmental Engineering, School of Engineering, Democritus University of Thrace, 67100 Xanthi, Greece e-mail: kliolios@env.duth.gr

K. N. Moutsopoulos

e-mail: kmoutso@env.duth.gr

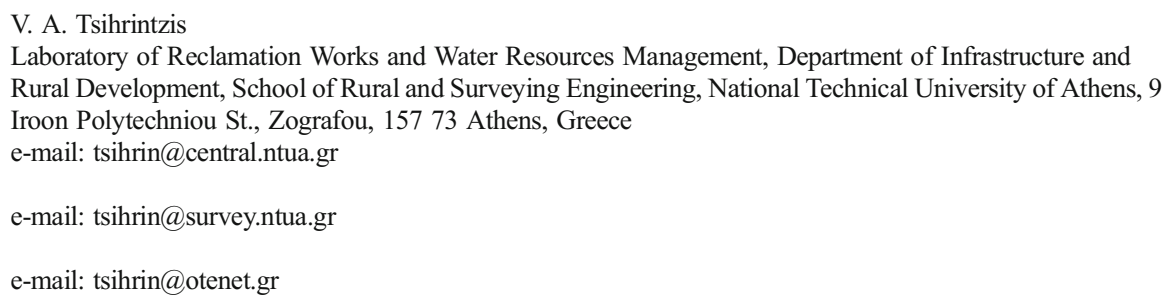




\section{Introduction}

Constructed wetlands (CWs) are a good alternative solution to treat municipal wastewater in small settlements (Kadlec and Wallace 2009). As the use of such systems is currently becoming very popular in many countries (Vymazal 2002; Tsihrintzis and Gikas 2010; Gikas and Tsihrintzis 2010) the need arises to investigate in depth their function and find their optimal design characteristics. In practical applications, the purpose is, on the one hand to maximize removal efficiency and on the other hand to minimize surface area and construction cost.

Among the parameters influencing the $\mathrm{CW}$ function, meteorological effects have a significant role (Kadlec and Wallace 2009). In this study, a numerical investigation on the effects of rainfall and evapotranspiration (ET) on CW performance is presented. Especially for horizontal subsurface flow constructed wetlands (HSF CW), operating under Mediterranean climate conditions, such effects can be significant for their performance and optimum design.

In this study, the objective is to quantify, based on modeling, the effects of rainfall and ET on the removal of Biochemical Oxygen Demand (BOD). First, the mathematical modeling of the problem is presented. For the numerical treatment, the Visual MODFLOW-MT3DMS computer code family is used. Next, the numerical procedure is applied for the simulation of five pilot-scale HSF CWs where experimental data exist (Akratos and Tsihrintzis 2007).

\section{Methods and Materials}

\subsection{Problem Formulation and Numerical Simulation}

Meteorological parameters, i.e., evapotranspiration (ET) and rainfall (P), affect the flow and contaminant fate in CWs. The partial differential equation, describing the general threedimensional fully-saturated groundwater flow, reads (Bear 1979):

$$
\frac{\partial}{\partial \mathrm{x}_{\mathrm{i}}}\left(\mathrm{K} \frac{\partial \mathrm{h}}{\partial \mathrm{x}_{\mathrm{i}}}\right)+\mathrm{q}_{\mathrm{s}}=\mathrm{S}_{\mathrm{s}} \frac{\partial \mathrm{h}}{\partial \mathrm{t}}
$$

where $x_{i}$ is the spatial coordinate [L]; $h$ is the hydraulic head [L]; $K$ is the hydraulic conductivity $\left[\mathrm{LT}^{-1}\right] ; S_{S}$ is the specific storage of the porous media $\left[\mathrm{L}^{-1}\right]$; and $q_{s}$ is the volumetric flow rate per unit volume of porous media, representing fluid sources (positive) and sinks (negative) $\left[\mathrm{T}^{-1}\right]$. This last term $q_{s}$ can be used to model the meteorological effects, i.e., rainfall and evapotranspiration, on the mass balance of wastewater in the CW.

The hydraulic head $h$ is used to compute the intrinsic velocity field using the Darcy law:

$$
\mathrm{v}_{\mathrm{i}}=-\frac{\mathrm{K}}{\theta} \frac{\partial \mathrm{h}}{\partial \mathrm{x}_{\mathrm{i}}}
$$

where $\theta[-]$ is the porosity of the porous medium. Finally, the partial differential equation, describing the fate and transient transport of a single contaminant in the 3-D groundwater flow system, can be written as follows (Zheng and Bennett 2002):

$$
\mathrm{R}_{\mathrm{d}} \frac{\partial(\theta \mathrm{C})}{\partial \mathrm{t}}=\frac{\partial}{\partial \mathrm{x}_{\mathrm{i}}}\left(\theta \mathrm{D}_{\mathrm{ij}} \frac{\partial \mathrm{C}}{\partial \mathrm{x}_{\mathrm{j}}}\right)-\frac{\partial}{\partial \mathrm{x}_{\mathrm{i}}}\left(\theta \mathrm{v}_{\mathrm{i}} \mathrm{C}\right)+\sum \mathrm{R}_{\mathrm{n}}
$$

where $C$ is the contaminant concentration $\left[\mathrm{ML}^{-3}\right] ; R_{d}$ is the retardation factor $[-] ; D_{i j}$ is the hydrodynamic dispersion coefficient tensor $\left[\mathrm{L}^{2} \mathrm{~T}^{-1}\right]$; $v_{i}$ is the seepage or intrinsic velocity 
$\left[\mathrm{LT}^{-1}\right]$; and $\Sigma R_{n}$ is the chemical reaction term $\left[\mathrm{ML}^{-3} \mathrm{~T}^{-1}\right]$. In this study, this last term, in the simplest linear case with no sorption, is assumed to depend on the first-order removal coefficient $\lambda$, and is equal to $-\lambda C$. Furthermore, the case of a non-sorbing contaminant, BOD, was considered, therefore, $R_{d}=1$.

As explained by Liolios et al. (2012), most HSF CWs can be modeled in two dimensions in the vertical plane along the facility, considering unconfined flow. Then, the flow Eq. (1) for the problem under consideration reduces to the Boussinesq equation (Bear 1979):

$$
\mathrm{S}_{\mathrm{y}} \frac{\partial(\mathrm{h})}{\partial \mathrm{t}}=\frac{\partial}{\partial \mathrm{x}}\left(\mathrm{Kh} \frac{\partial \mathrm{h}}{\partial \mathrm{x}}\right)+\frac{\partial}{\partial \mathrm{y}}\left(\mathrm{Kh} \frac{\partial \mathrm{h}}{\partial \mathrm{y}}\right)+\mathrm{P}-\mathrm{ET}
$$

where $P$ is the precipitation [LT $\left.{ }^{-1}\right]$; ET is the evapotranspiration $\left[\mathrm{LT}^{-1}\right] ; \mathrm{S}_{\mathrm{y}}$ is the specific yield; $x$ is the longitudinal coordinate and $y$ is the vertical coordinate. As well-known, the Boussinesq equation is a non-linear partial differential equation, which is usually solved by linearization techniques (Bear 1979).

In practical applications, the numerical solution of the above problem can be obtained by using a suitable numerical method. As the HSF CWs modeled here have a rectangular cross section (see following section), the Finite Difference Method was selected. This method is the basis for the MODFLOW (Modular Finite-Difference Ground-Water Flow Model) code. Details about this code are given in Harbaugh and McDonald (1996), Waterloo Hydrogeologic, Inc. (2006) and Batu (2006). MODFLOW is well-known and widely used for the simulation of groundwater flow and mass transport. Regarding ET computations, MODFLOW includes a special evapotranspiration package. In the present study, the program MT3DMS (Modular 3-Dimensional Multi Species Transport) (Zheng 1990) was used in conjuction with MODFLOW for the simulation of BOD fate in the pilot-scale units described in the next section.

\subsection{Pilot-scale Units Description}

The effects of rainfall and ET were investigated using available experimental data from five pilot-scale HSF CW units. A detailed description of these facilities is given by Akratos and Tsihrintzis (2007). Briefly, the units were rectangular tanks with various porous media (i.e., medium gravel: MG; fine gravel: FG; and cobbles: $\mathrm{CO}$ ) and plants (i.e., reed: R; cattails: C; and unplanted tank: $Z$ ). The dimensions of each tank were $3.0 \mathrm{~m}$ long, $0.75 \mathrm{~m}$ wide and $0.45 \mathrm{~m}$ deep. The effluent wastewater level was controlled at the outlet at the top of the porous medium $(0.45 \mathrm{~m})$. A typical longitudinal section is presented in Fig. 1a. The tanks operated continuously for 2 years (2004-2006) in parallel experiments, at hydraulic residence times (HRTs) of 6, 8, 14 and 20 days.

For MODFLOW application, the space discretization of the computation domain in each CW unit was made using 210 columns and 40 layers, i.e., each layer had 210 cells (Fig. 1b). The first upper left cell was the inlet cell. Regarding the boundary conditions of the hydraulic field, a condition of constant head $(0.45 \mathrm{~m})$ was imposed at the outlet right cell of the bottom layer, according to the experimental procedure (Akratos and Tsihrintzis 2007) and the usual operation of HSF CWs. This was the case when the subtracted flow rate $Q_{E T}$ due to ET was less than the inflowing wastewater flow rate $Q_{i n}$. When $Q_{E T}$ was expected to be greater than $Q_{i n}$, the wastewater level in the $\mathrm{CW}$ unit would drop below the outlet control level of $0.45 \mathrm{~m}$, and there would not be any outflow from the unit. In this case, a no-flow BC was imposed at the outlet. Regarding the inflow boundary conditions, the Recharge package of MODFLOW was used for the inlet cell region. For additional simulation details, see also Liolios et al. (2012). 


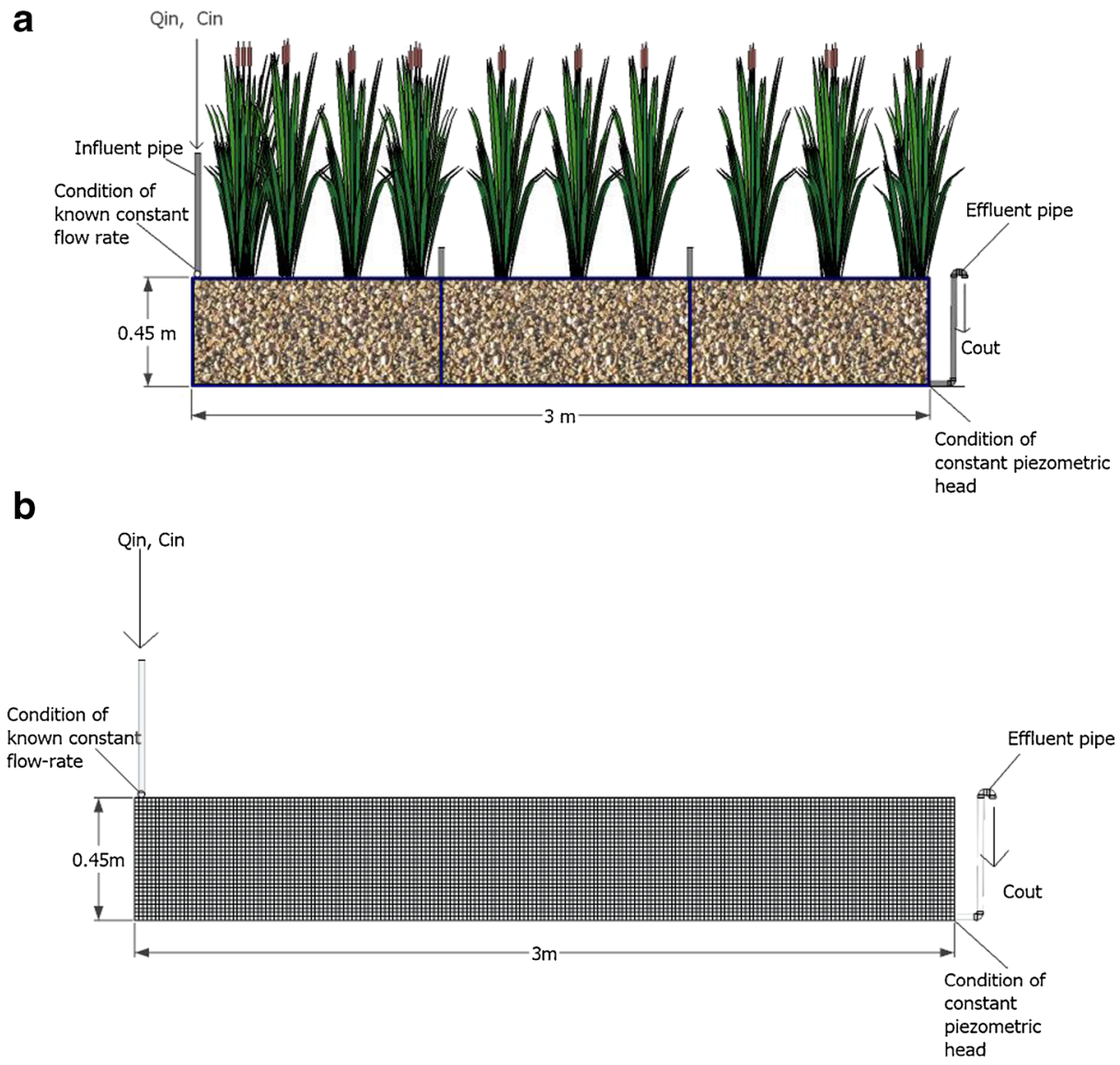

Fig. 1 a Schematic cross-section of the CW facilities; b Computational grid and boundary conditions (Liolios et al. 2012)

\subsection{Evaluation of Rainfall and ET Values}

During the experiments (2004-2006) described above, meteorological data were collected in a weather station located adjacent to the $\mathrm{CW}$ facilities. These data included, among others, solar radiation, air and soil temperature, relative humidity, wind speed and daily values of rainfall depth. ET was estimated for each pilot-scale unit, using the above available meteorological data.

For the estimation of the ET in HSF CWs, various methods are available in the literature (e.g., Kadlec and Wallace 2009; Lott and Hunt 2001; Papaevangelou et al. 2012a, b). These include, among others, the: Turc, Thornthwaite, Hargreaves, Blaney-Criddle, PenmanMonteith, Priestley-Taylor, etc. Among these methods, the Blaney-Criddle was selected here, which was calibrated and proposed by Papaevangelou et al. (2012a) based on direct ET measurements in the pilot-scale units. Briefly, the computation of ET is based on the following equations:

where:

$$
\mathrm{ET}_{\mathrm{BC}}=\left(\mathrm{k}_{\mathrm{t}}\right) \cdot\left(\mathrm{k}_{\mathrm{c}}\right) \cdot \mathrm{f}
$$




$$
\begin{gathered}
\mathrm{k}_{\mathrm{t}}=0.03114 \mathrm{~T}_{\alpha}+0.24 \\
\mathrm{k}_{\mathrm{c}}=0.472+0.273 \mathrm{Jr}+8.53 \mathrm{Jr}^{2}-24.4 \mathrm{Jr}^{3}+24.3 \mathrm{Jr}^{4}-8.8 \mathrm{Jr}^{5} \\
\mathrm{Jr}=\frac{\mathrm{M}+\frac{\mathrm{D}}{30.5}-1}{12} \\
\mathrm{f}=\left(0.46 \mathrm{~T}_{\alpha}+8.13\right) \cdot \mathrm{p}
\end{gathered}
$$

In the above relations, $T_{\alpha}$ is the mean daily air temperature $\left[{ }^{\circ} \mathrm{C}\right] ; k_{t}$ is the climatic coefficient which depends on air temperature $T_{\alpha} ; k_{c}$ is a crop growth stage coefficient; $J r$ is a season coefficient which depends on the month; $M$ is the month index $(M=1,2, \ldots, 12) ; D$ is the index for the day of the month $(D=1,2, \ldots ., 31) ; f$ is a consumptive-use factor; and $p$ is the mean daily percentage of annual daytime hours [\%].

The above method was used to estimate ET values for each CW unit (MG-R, MG-C, MG$\mathrm{Z}, \mathrm{FG}-\mathrm{R}, \mathrm{CO}-\mathrm{R}$ ) in combination with relevant plant/CW coefficients provided by Papaevangelou et al. (2012a), as follows:

$$
\begin{aligned}
& E T_{M G-R}=2.138 E T_{B C} \\
& E T_{M G-C}=2.092 E T_{B C} \\
& E T_{M G-Z}=0.512 E T_{B C} \\
& E T_{F G-R}=2.418 E T_{B C} \\
& E T_{C O-R}=2.511 E T_{B C}
\end{aligned}
$$

\section{Results and Discussion}

\subsection{MODFLOW Calibration by Using the Experimental Results}

Based on the experimental data by Akratos and Tsihrintzis (2007), first a calibration of MODFLOW code was realized by applying a sensitivity analysis. Then, the determination of the first order removal coefficient $\lambda$, relevant to the chemical reaction term $\Sigma R_{n}$ in Eq. (1), was obtained by adopting a trial-and-error procedure, and the optimal range of $\lambda$ values for BOD removal was estimated in terms of temperature and HRT. Details for the above simulations are described by Liolios et al. (2012).

\subsection{Effects of Rainfall on HSF CW Performance}

According to the meteorological data, the period, when the highest values of rainfall during the experimental period were recorded, was from 26 November 2005 until 25 December 2005. The daily rainfall values are shown in the following Table 1. These values were used in the MODFLOW Recharge package for the upper layer cells.

The results of the rainfall effects are summarized in Table 2. According to HRT and $\mathrm{CW}$ unit, first the average temperature $T_{a v}$ and the average concentration $C_{i n, a v}$ are shown. Next, the values of outlet concentration $C_{\text {out av }}$ and $C^{P}$ out,av are presented, with rainfall (P), respectively, not taken and taken into account in the computations. Finally, the percent decrease of $C^{P}{ }_{\text {out,av }}$ compared to $C_{\text {out }, \text { av }}$ is presented. The decrease of $C_{\text {out }}$ indicates that rainfall dilutes wastewater.

Representative results for the MODFLOW simulation of the tank MG-R concerning BOD removal, for HRT of 8 days and for an inlet contaminant concentration $\left(C_{i n}\right)$ of $369.4 \mathrm{mg} \mathrm{BOD} /$ $\mathrm{L}$, are as follows: 
(a) When rainfall is not taken into account, the outlet concentration value $\left(C_{\text {out }}\right)$ is $61.5 \mathrm{mg} / \mathrm{L}$.

(b) When rainfall is taken into account, the value of $C_{\text {out }}$ is $59.8 \mathrm{mg} / \mathrm{L}$.

In Fig. 2, representative profiles of BOD concentration, in [mg/L], are shown for the above two cases, without and with rainfall. The effect of rainfall is obvious in totally changing the iso-concentration contours.

As Table 2 shows, similar reductions of the outlet concentration were also recorded for all the other tanks and for different HRTs. This reduction is considered relatively small. The impact of rainfall is on one hand to reduce the HRT in the HSF CW (because of the additional flow and given that the facility capacity remains the same due to the outlet water level control), something that would increase effluent concentrations. However, on the other hand, the rainfall dilutes the wastewater, leading to smaller effluent concentrations. Apparently, the two processes nearly counterbalance each other, with the second only slightly reducing the effluent concentration at least for the rainfall depths tested.

\subsection{Effects of ET on HSF CW Performance}

As mentioned, the Blaney-Criddle method was calibrated by Papaevangelou et al. (2012a) to predict mean daily evapotranspiration $\left(E T_{B C}\right)$ in the HSF CWs. In order to simulate the effects of evapotranspiration in each $\mathrm{CW}$, the ET mean daily values were estimated using Eqs. (10a10e), for each CW unit (MG-R, MG-C, MG-Z, FG-R, CO-R). These values, shown in Table 3 as $E T_{a v}$ values, were introduced to MODFLOW. The special evapotranspiration package, included in MODFLOW, was used. This package computes evapotranspiration as a linear function of the depth below the top of the porous medium, i.e., the ET rate decreases linearly with depth; the extinction depth here was taken as $0.45 \mathrm{~m}$ which is the thickness of the porous medium (Fig. 1a). This is eventually a conservative approach, which might underestimate the effects of evapotranspiration.

Table 1 Daily rainfall and mean daily temperature for the period 26 November 2005 to 25 December 2005

\begin{tabular}{lclllc}
\hline Date & $\begin{array}{l}\text { Daily rainfall } \\
{[\mathrm{mm} / \mathrm{d}]}\end{array}$ & $\begin{array}{l}\text { Mean daily } \\
\text { temperature }\left[{ }^{\circ} \mathrm{C}\right]\end{array}$ & Date & $\begin{array}{l}\text { Daily rainfall } \\
{[\mathrm{mm} / \mathrm{d}]}\end{array}$ & $\begin{array}{l}\text { Mean daily } \\
\text { temperature }\left[{ }^{\circ} \mathrm{C}\right]\end{array}$ \\
\hline $26 / 11 / 2005$ & 23.2 & 4.5 & $11 / 12 / 2005$ & 6.6 & 12.0 \\
$27 / 11 / 2005$ & 12.4 & 8.7 & $12 / 12 / 2005$ & 0.0 & 13.4 \\
$28 / 11 / 2005$ & 26.4 & 10.3 & $13 / 12 / 2005$ & 0.4 & 10.2 \\
$29 / 11 / 2005$ & 0.0 & 10.2 & $14 / 12 / 2005$ & 0.0 & 8.7 \\
$30 / 11 / 2005$ & 3.2 & 11.8 & $15 / 12 / 2005$ & 0.0 & 6.9 \\
$1 / 12 / 2005$ & 0.2 & 13.0 & $16 / 12 / 2005$ & 1.2 & 6.8 \\
$2 / 12 / 2005$ & 0.0 & 10.8 & $17 / 12 / 2005$ & 0.0 & 7.4 \\
$3 / 12 / 2005$ & 0.8 & 11.5 & $18 / 12 / 2005$ & 12.4 & 6.3 \\
$4 / 12 / 2005$ & 7.4 & 14.5 & $19 / 12 / 2005$ & 17.8 & 7.7 \\
$5 / 12 / 2005$ & 15.8 & 15.2 & $20 / 12 / 2005$ & 0.0 & 2.2 \\
$6 / 12 / 2005$ & 0.0 & 12.1 & $21 / 12 / 2005$ & 0.9 & 1.6 \\
$7 / 12 / 2005$ & 0.4 & 12.5 & $22 / 12 / 2005$ & 1.7 & 3.5 \\
$8 / 12 / 2005$ & 0.0 & 9.9 & $23 / 12 / 2005$ & 2.2 & 4.2 \\
$9 / 12 / 2005$ & 0.0 & 10.4 & $24 / 12 / 2005$ & 0.8 & 8.8 \\
$10 / 12 / 2005$ & 0.2 & 10.3 & $25 / 12 / 2005$ & 34.8 & 11.7 \\
\hline
\end{tabular}


Table 2 Results of rainfall effects on HSF CW performance

\begin{tabular}{|c|c|c|c|c|c|c|}
\hline HRT [days] & CW unit & $T_{a v}\left[{ }^{\circ} \mathrm{C}\right]$ & $C_{i n, a v}[\mathrm{mg} / \mathrm{L}]$ & $C_{\text {out }, a v}[\mathrm{mg} / \mathrm{L}]$ & $C_{\text {out }, a v}^{P}[\mathrm{mg} / \mathrm{L}]$ & Decrease of $\mathrm{C}_{\text {out }}[\%]$ \\
\hline \multirow[t]{5}{*}{6} & MG-R & 15.1 & 332.6 & 83.7 & 81.9 & 2.15 \\
\hline & MG-C & & & 76.2 & 74.5 & 2.23 \\
\hline & MG-Z & & & 67.2 & 65.6 & 2.38 \\
\hline & FG-R & & & 65.4 & 63.8 & 2.43 \\
\hline & CO-R & & & 84.2 & 82.5 & 2.05 \\
\hline \multirow[t]{5}{*}{8} & MG-R & 12.6 & 369.4 & 61.5 & 59.8 & 2.76 \\
\hline & MG-C & & & 29.7 & 28.9 & 2.86 \\
\hline & MG-Z & & & 58.2 & 57.0 & 2.06 \\
\hline & FG-R & & & 28.7 & 27.9 & 2.79 \\
\hline & CO-R & & & 45.1 & 44.0 & 2.44 \\
\hline \multirow[t]{5}{*}{14} & MG-R & 16.2 & 389.4 & 24.4 & 23.6 & 3.28 \\
\hline & MG-C & & & 36.3 & 35.0 & 3.58 \\
\hline & MG-Z & & & 40.0 & 38.6 & 3.50 \\
\hline & FG-R & & & 36.8 & 35.5 & 3.53 \\
\hline & CO-R & & & 42.9 & 41.4 & 3.50 \\
\hline \multirow[t]{5}{*}{20} & MG-R & 15.2 & 357.6 & 35.0 & 33.8 & 3.43 \\
\hline & MG-C & & & 29.5 & 28.4 & 3.73 \\
\hline & MG-Z & & & 37.4 & 36.5 & 2.41 \\
\hline & FG-R & & & 27.7 & 26.7 & 3.61 \\
\hline & CO-R & & & 24.2 & 23.3 & 3.72 \\
\hline
\end{tabular}

(a)

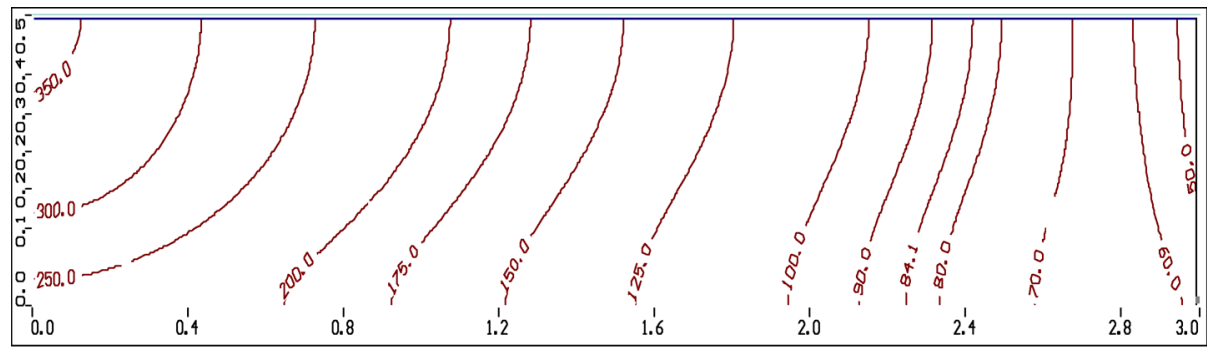

(b)

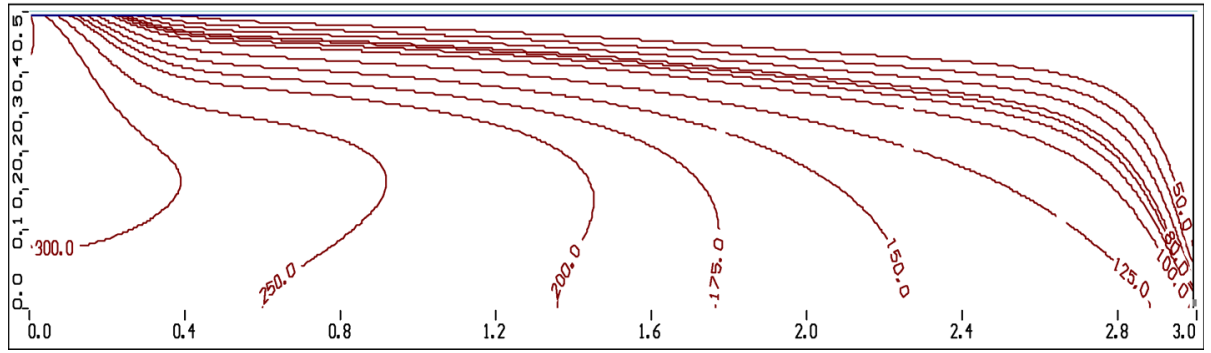

Fig. 2 Profiles of BOD concentration, in [mg/L], for the MG-R unit, with average temperature $12.6{ }^{\circ} \mathrm{C}$ and $\mathrm{HRT}$ of 8 days, when: a rainfall is not taken into account; $\mathbf{b}$ rainfall is taken into account 
Table 3 Results of ET effects on HSF CW performance

\begin{tabular}{|c|c|c|c|c|c|c|c|}
\hline HRT [days] & $\mathrm{CW}$ unit & $T_{a v}\left[{ }^{\circ} \mathrm{C}\right]$ & $\begin{array}{l}C_{i n, a v} \\
{[\mathrm{mg} / \mathrm{L}]}\end{array}$ & $\begin{array}{l}E T_{a v} \\
{[\mathrm{~mm} / \mathrm{d}]}\end{array}$ & $\begin{array}{l}C_{\text {out }, a v} \\
{[\mathrm{mg} / \mathrm{L}]}\end{array}$ & $\begin{array}{l}C_{\text {out,av }}^{E T} \\
{[\mathrm{mg} / \mathrm{L}]}\end{array}$ & $\begin{array}{l}\text { Increase of } \\
\mathrm{C}_{\text {out }}[\%]\end{array}$ \\
\hline \multirow[t]{5}{*}{6} & MG-R & 15.1 & 332.6 & 7.96 & 83.7 & 100.8 & 20.43 \\
\hline & MG-C & & & 7.79 & 76.2 & 95.0 & 24.67 \\
\hline & MG-Z & & & 1.91 & 67.2 & 69.7 & 3.72 \\
\hline & FG-R & & & 9.00 & 65.4 & 74.6 & 14.07 \\
\hline & $\mathrm{CO}-\mathrm{R}$ & & & 9.35 & 84.2 & 90.1 & 7.01 \\
\hline \multirow[t]{5}{*}{8} & MG-R & 12.6 & 369.4 & 2.75 & 61.4 & 65.8 & 7.17 \\
\hline & MG-C & & & 2.71 & 29.7 & 34.6 & 16.50 \\
\hline & MG-Z & & & 0.66 & 58.2 & 59.0 & 1.37 \\
\hline & FG-R & & & 2.89 & 28.7 & 40.7 & 41.81 \\
\hline & CO-R & & & 6.00 & 45.1 & 63.7 & 41.24 \\
\hline \multirow[t]{5}{*}{14} & MG-R & 16.2 & 389.4 & 6.33 & 24.6 & 40.0 & 63.93 \\
\hline & MG-C & & & 6.13 & 36.3 & 60.1 & 65.56 \\
\hline & MG-Z & & & 1.51 & 40.0 & 44.1 & 10.25 \\
\hline & FG-R & & & 7.16 & 36.8 & a & a \\
\hline & CO-R & & & 7.44 & 42.9 & a & $\mathrm{a}$ \\
\hline \multirow[t]{5}{*}{20} & MG-R & 15.2 & 357.6 & 5.63 & 35.0 & 66.2 & 89.14 \\
\hline & MG-C & & & 5.45 & 29.5 & 59.0 & 100.0 \\
\hline & MG-Z & & & 1.40 & 37.4 & 42.2 & 12.83 \\
\hline & FG-R & & & 6.59 & 27.7 & a & a \\
\hline & CO-R & & & 6.84 & 24.2 & a & a \\
\hline
\end{tabular}

${ }^{\mathrm{a}}$ Indicates cases when $\mathrm{Q}_{\mathrm{in}}<\mathrm{Q}_{\mathrm{ET}}$ with no outflow from the $\mathrm{CW}$

The results of the ET effects are summarized in Table 3. According to HRT and CW unit, first the average temperature $T_{a v}$ and the average concentration $C_{i n, a v}$ are shown. The values of average $E T_{a v}$ have been evaluated as described above. Next, the values of outlet concentration $C_{\text {out }, a v}$ and $C^{E T}$ out,av are presented, with ET, respectively, not taken and taken into account in the computations. Finally, the percent increase of $C^{E T}{ }_{\text {out,av }}$ compared to $C_{\text {out }, a v}$ is presented for the cases when the incoming flow rate $Q_{i n}[\mathrm{~L} / \mathrm{d}]$ remained greater than the subtracted $Q_{E T}$ due to ET. The increase of $C_{\text {out }}$ indicates that ET condenses wastewater.

Representative results for the MODFLOW simulation of the tank MG-R, when the incoming flow rate $Q_{i n}$ remained greater than the subtracted $Q_{E T}$ due to ET, are shown in Fig. 3. These results concern BOD removal for HRT of 14 days and for an inlet contaminant concentration $\left(C_{i n}\right)$ of $389.4 \mathrm{mg} / \mathrm{L}$. BOD concentration fields, in [mg/L], are depicted for the two cases:

(a) When ET is not taken into account, the outlet concentration value $\left(C_{\text {out }}\right)$ is about $24.6 \mathrm{mg} / \mathrm{L}$.

(b) When ET is taken into account, the value of $C_{\text {out }}$ is about $40 \mathrm{mg} / \mathrm{L}$.

In Fig. 3, representative profiles of the BOD concentration, in $[\mathrm{mg} / \mathrm{L}]$, are shown for the two cases, without and with ET. The effect of ET on the iso-concentration contours is obvious.

Table 3 also contains cells with no effluent concentration, which denotes cases with $Q_{i n}<$ $Q_{E T}$. These extreme cases occur during some summer days when ET is high and, in addition, the HRT was relatively high. In such cases, the wastewater level in the CW unit dropped below the outlet control level of $0.45 \mathrm{~m}$, and there was no outflow from the unit. As mentioned, in order to 
(a)

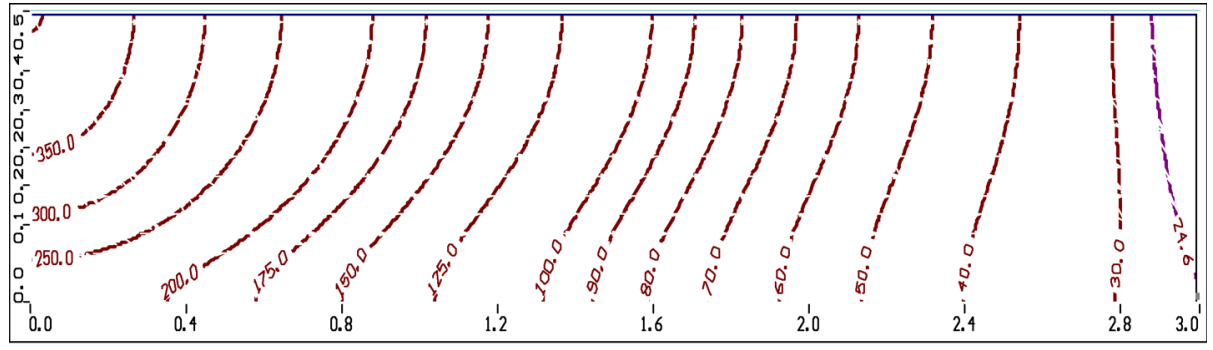

(b)

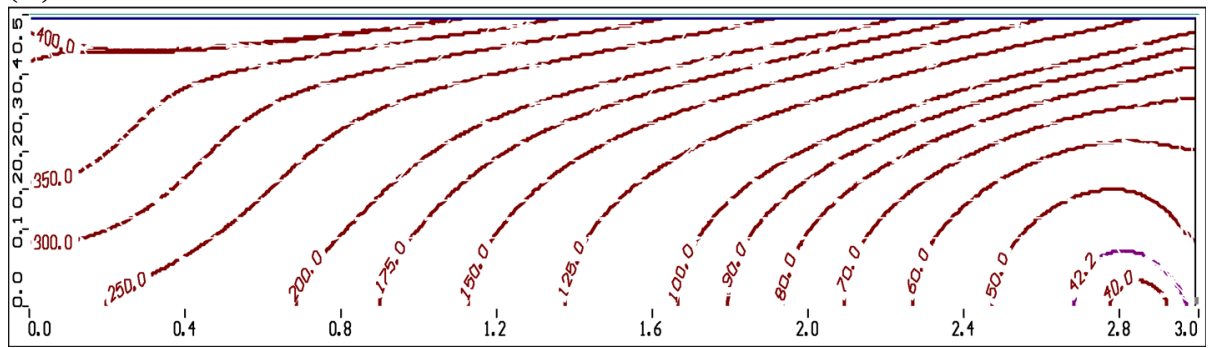

Fig. 3 Profiles of BOD concentration, in [mg/L], for the MG-R unit, with average temperature $16.2{ }^{\circ} \mathrm{C}$ and $\mathrm{HRT}$ of 14 days, when $\mathrm{Q}_{i n}>\mathrm{Q}_{E T}$ : a ET is not taken into account; $\mathbf{b}$ ET is taken into account

simulate this case $\left(Q_{i n}<Q_{E T}\right)$, a no-flow BC was imposed at the outlet cell. The model successfully modeled the decline of water table in the CW, as shown in Fig. 4 for the FG-R unit and a HRT of 20 days.

\subsection{Combined effect of ET and other HSF CW Operational and Design Parameters}

The model was used with the values of the decay coefficient $\lambda\left[\mathrm{d}^{-1}\right]$ derived from empirical equations presented by Liolios et al. (2012), relating this coefficient to temperature and HRT. The purpose was to test the influence of vegetation, temperature, porosity and HRT on BOD concentration prediction under conditions with and without the influence of ET. Results include BOD concentration profiles along the centerline of the $\mathrm{CW}$ unit, as presented in

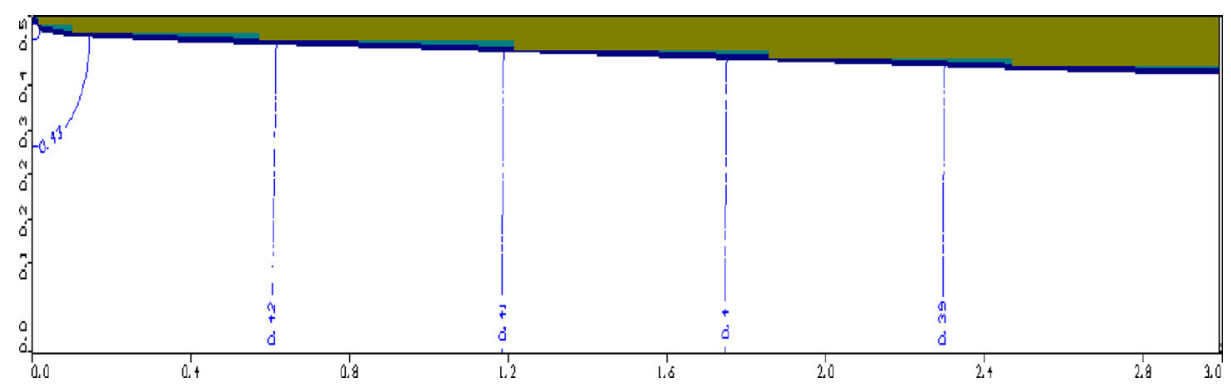

Fig. 4 Profile of piezometric head, in [m], for CW unit FG-R, with average temperature $15.2^{\circ} \mathrm{C}$ and for HRT of 20 days, when $\mathrm{Q}_{i n}<\mathrm{Q}_{E T}$ 
(a)
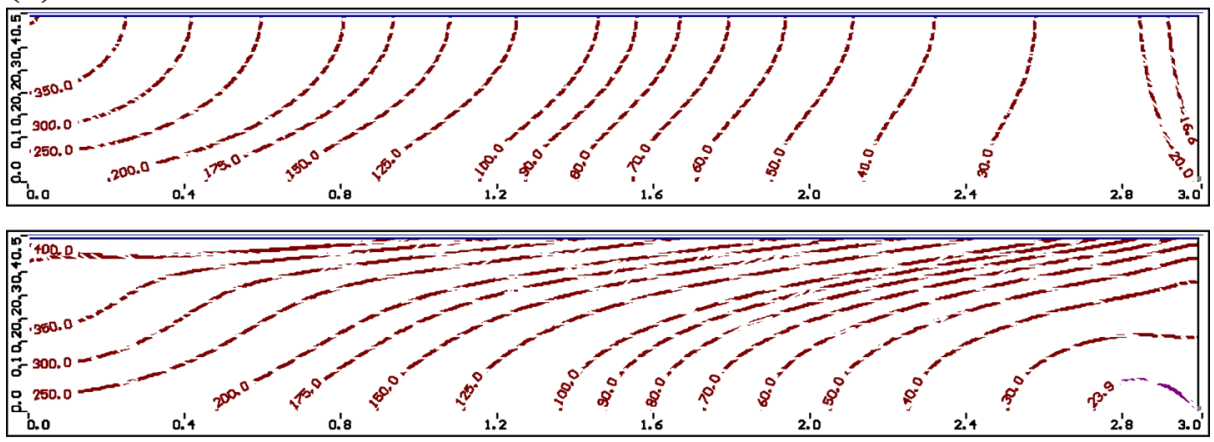

(b)
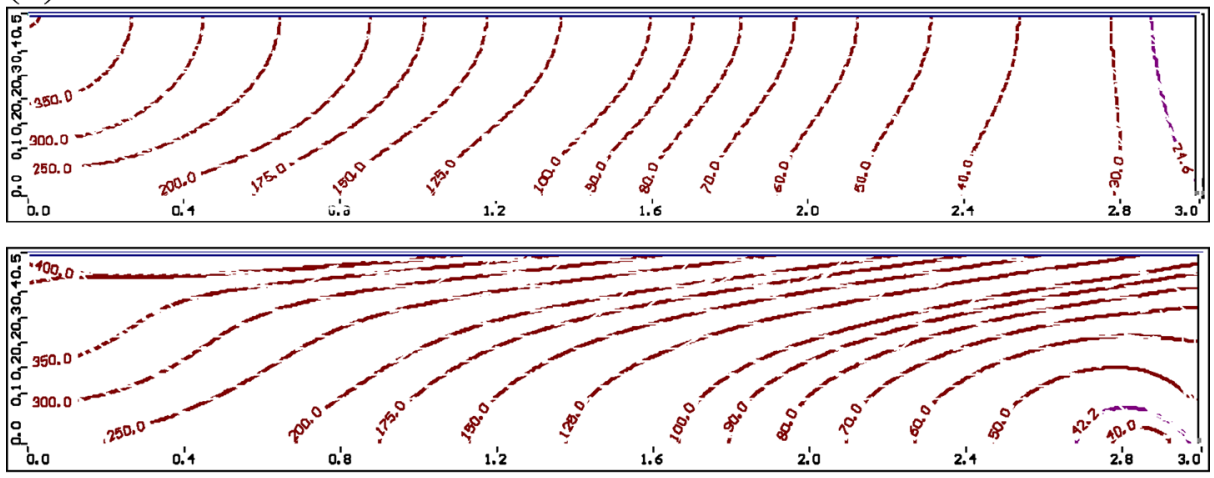

(c)
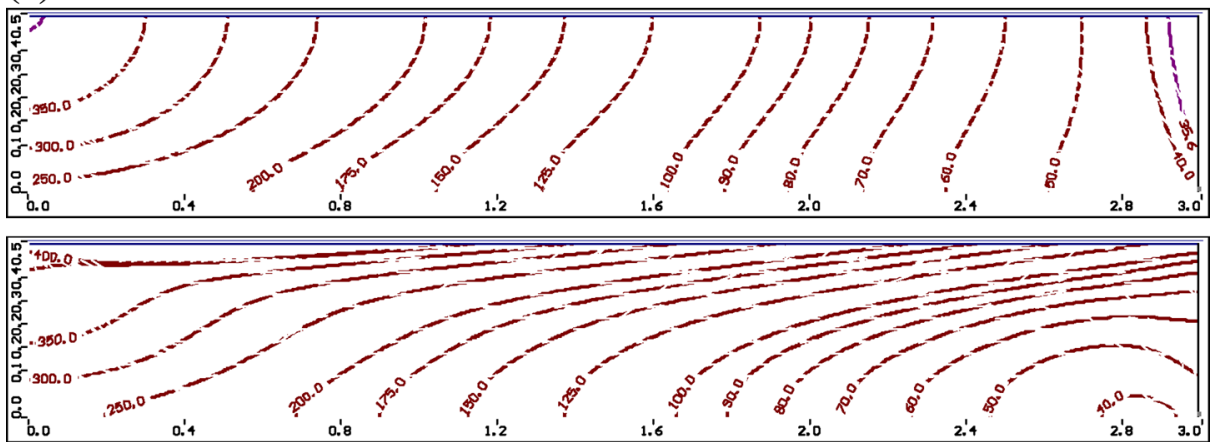

Fig. 5 Effect of ET on BOD removal for different vegetation types (Temperature: $20{ }^{\circ} \mathrm{C}$; HRT: 14 days). Profiles of BOD concentration, in [mg/L], without (upper graph) and with (lower graph) ET for CW units: a MG-R; b MG-C; c MG-Z)

Figs. 5, 6, 7, and 8. Effluent concentrations are presented in Tables 4, 5, 6, and 7. In all cases, the influent BOD concentration in the CW units was $400 \mathrm{mg} / \mathrm{L}$.

\subsubsection{Combined Effect of ET and Vegetation}

To test the influence of vegetation, the CW units MG-R, MG-C and MG-Z were modeled. These are filled with the same porous medium (medium gravel) but are planted with different 
(a)
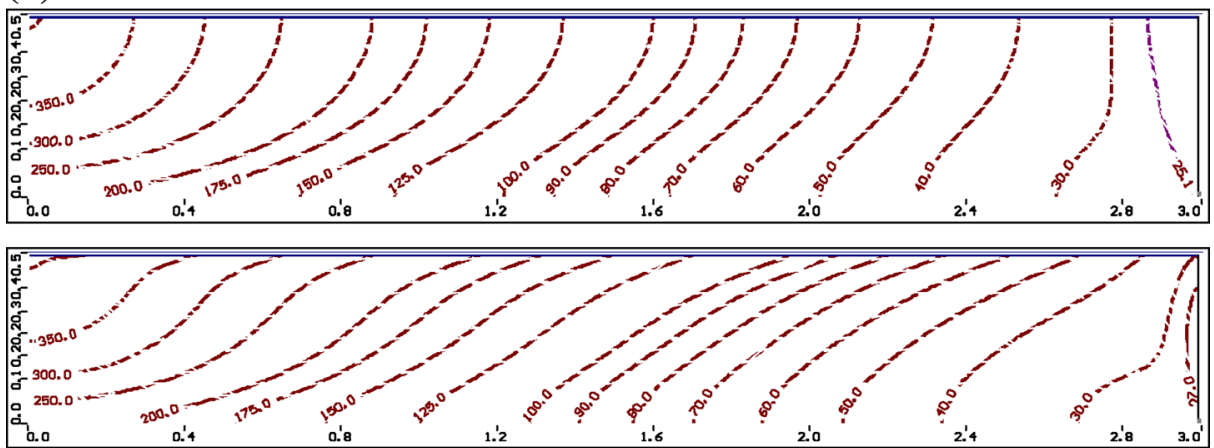

(b)
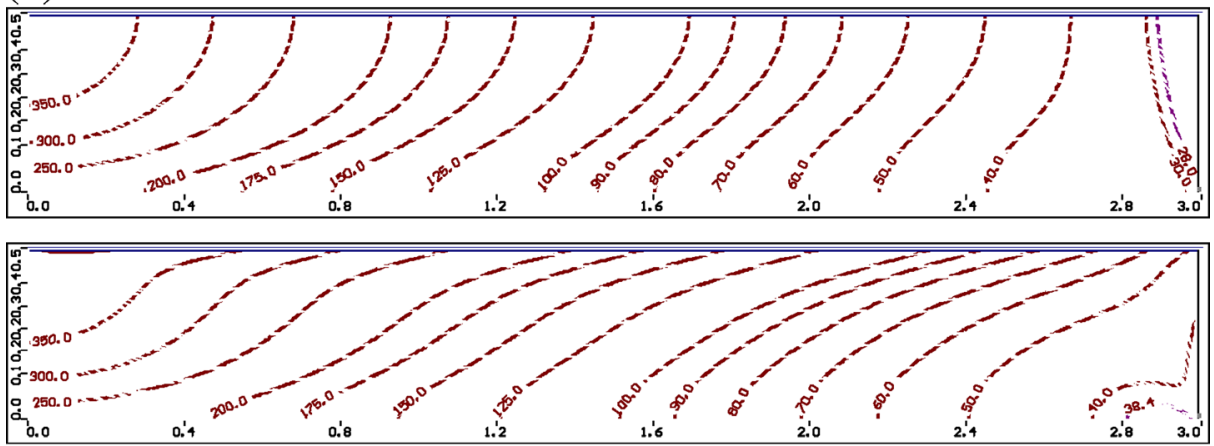

(c)
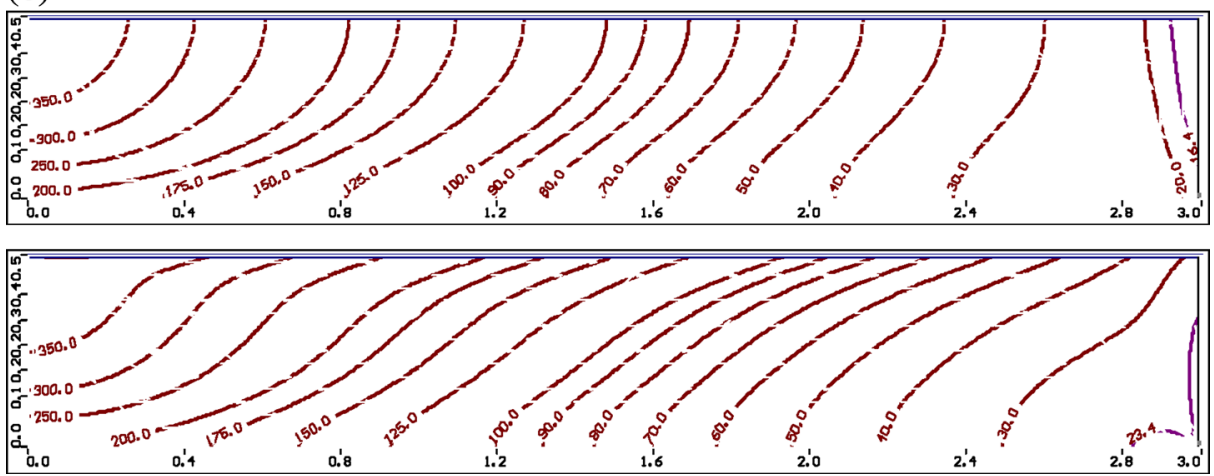

Fig. 6 Effect of ET on BOD removal for different porous media material sizes (Temperature: $20^{\circ} \mathrm{C}$; HRT: 8 days). Profiles of BOD concentration, in $[\mathrm{mg} / \mathrm{L}]$, without (upper graph) and with (lower graph) ET for CW units: a MG-R; b FG-R; c CO-R

vegetation type, i.e., common reed, cattails, and unplanted, respectively (Akratos and Tsihrintzis 2007). The temperature was set at $20{ }^{\circ} \mathrm{C}$ and the HRT was 14 days. Modeling was for both, with and without ET. The results are presented in Table 4 for the three CWs. Table 4 shows the $\lambda\left[\mathrm{d}^{-1}\right]$ value used (Liolios et al. 2012), the ET in $\mathrm{mm} / \mathrm{d}$, effluent BOD concentrations with and without ET, and the percent increase of effluent concentration when considering ET. Figure 5 presents the representative profiles of BOD concentration along each 
(a)
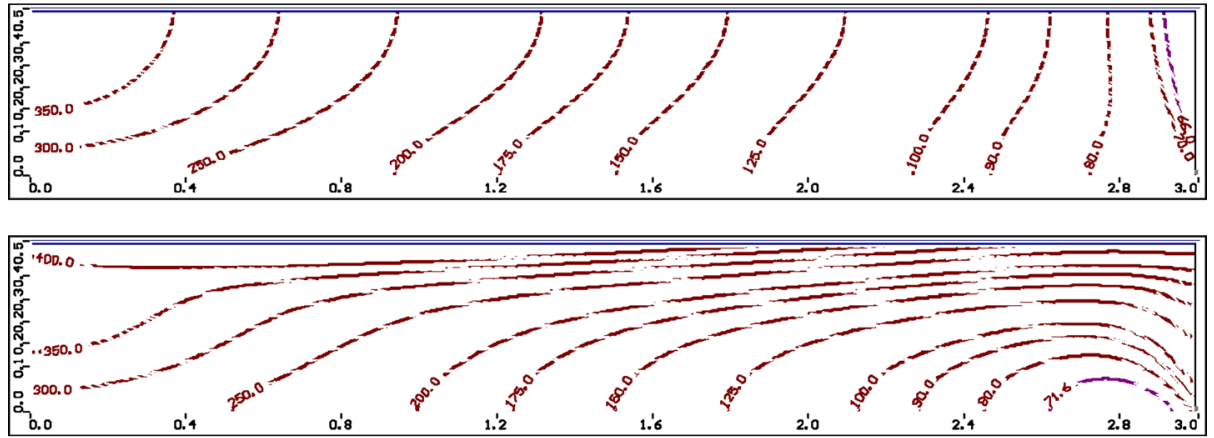

(b)
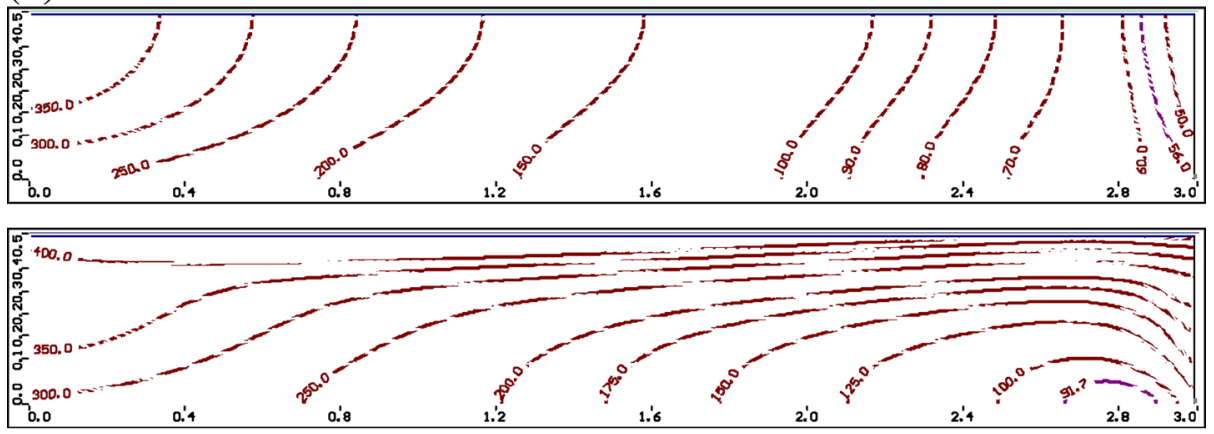

(c)
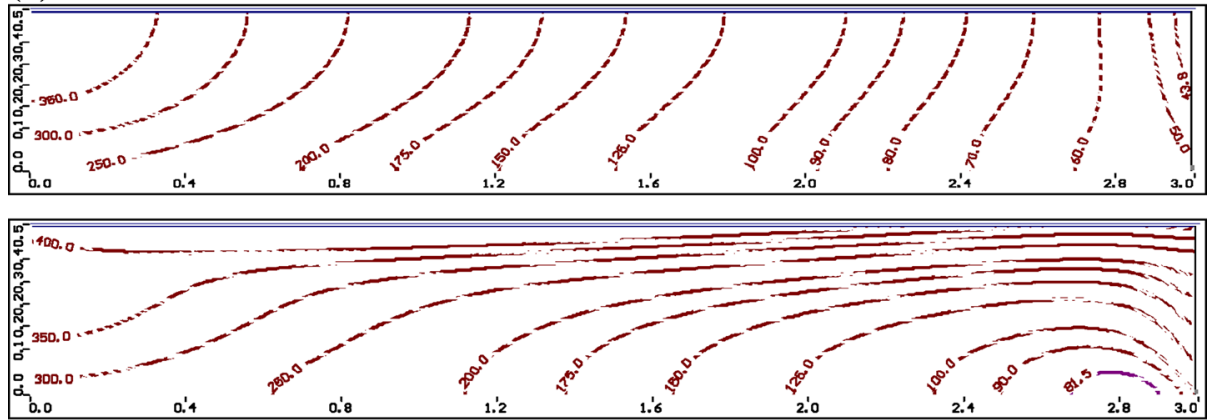

(d)
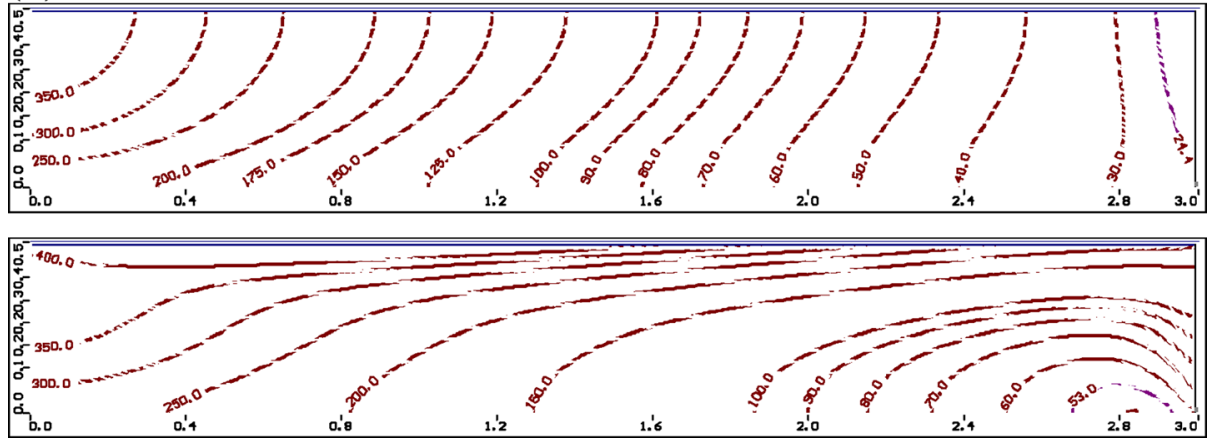
Fig. 7 Effect of ET on BOD removal for different HRTs (Temperature: $15^{\circ} \mathrm{C}$ ). Profiles of BOD concentration, in [mg/L], without (upper graph) and with (lower graph) ET for CW unit MG-R and for HRT: a 6 days; b 8 days; c 14 days; $\mathbf{d} 20$ days

$\mathrm{CW}$ when ET is not taken and when it is taken into account. The results show that the influence of ET on HSF CW BOD removal, according to vegetation, was more pronounced for cattails (MG-C) than for common reed (MG-R). As expected, the ET influence was the lowest for the unplanted (MG-Z) unit.

(a)
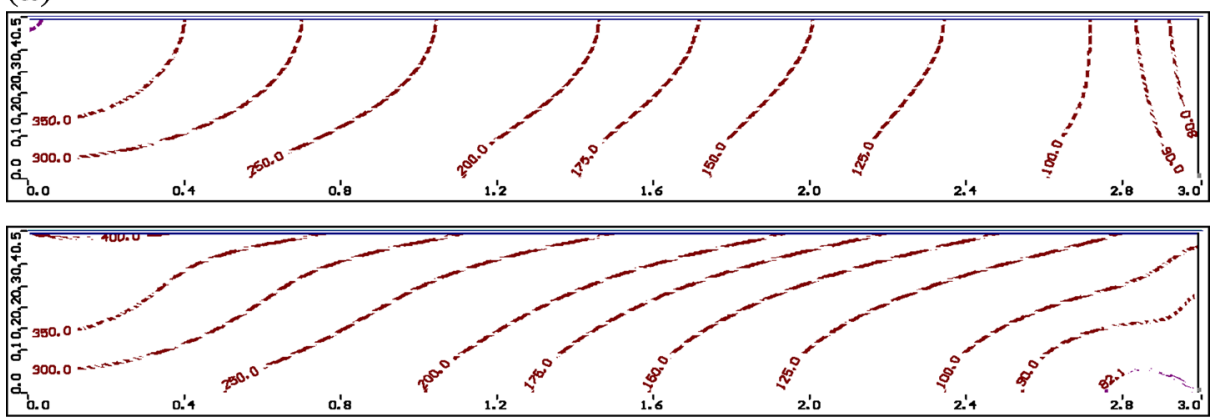

(b)
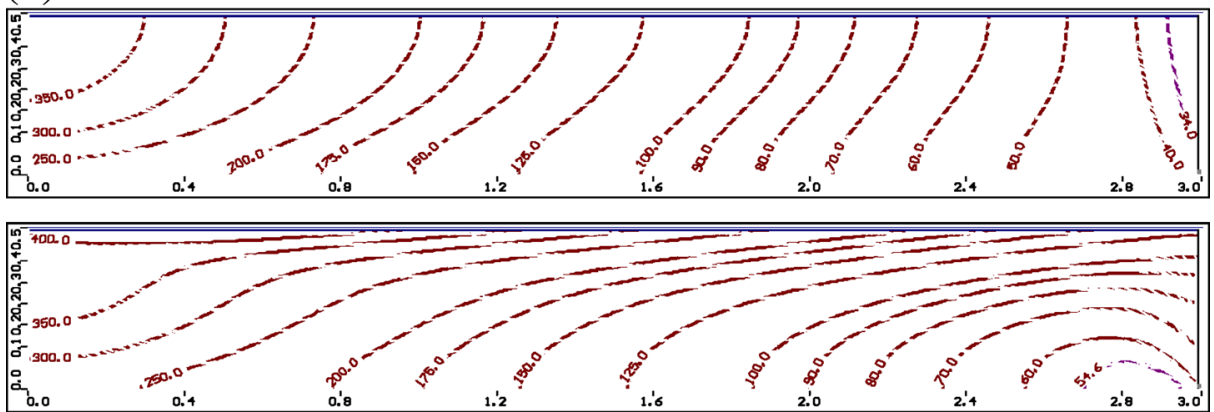

(c)
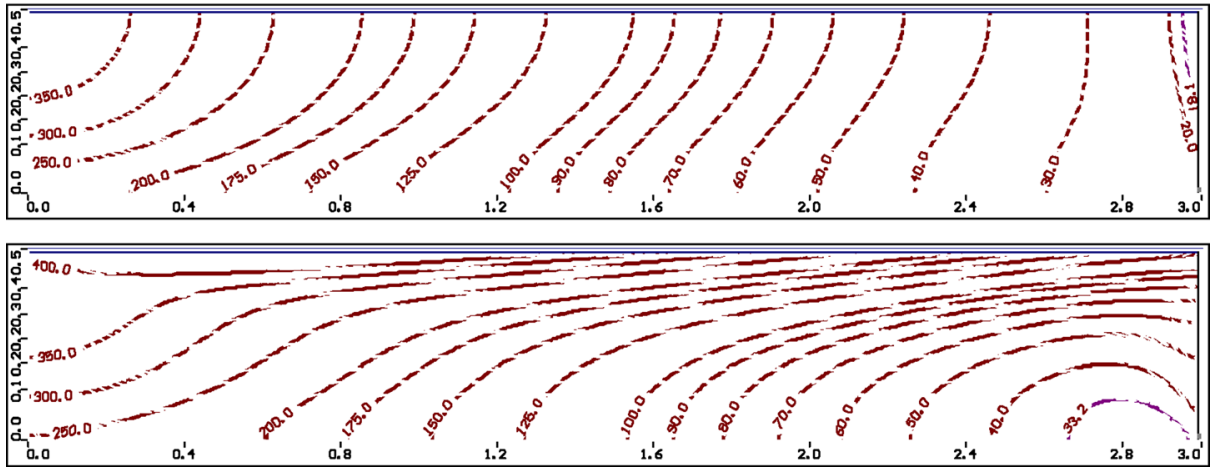

Fig. 8 Effect of ET on BOD removal according to temperature (HRT: 8 days). Profiles of BOD concentration, in $[\mathrm{mg} / \mathrm{L}]$, without (upper graph) and with (lower graph) ET for CW unit FG-R and for temperature: a $8{ }^{\circ} \mathrm{C}$; b $15{ }^{\circ} \mathrm{C} ; \mathbf{c} 20^{\circ} \mathrm{C}$ 
Table 4 Combined effect of ET and vegetation type on BOD effluent concentrations (Temperature: $20^{\circ} \mathrm{C}$; HRT: 14 days)

\begin{tabular}{llllll}
\hline CW unit & $\lambda\left[\mathrm{d}^{-1}\right]$ & $\mathrm{ET}[\mathrm{mm} / \mathrm{d}]$ & $\mathrm{C}_{\text {out }}[\mathrm{mg} / \mathrm{L}]$ & $\mathrm{C}^{\mathrm{ET}}{ }_{\text {out }}[\mathrm{mg} / \mathrm{L}]$ & Increase of $\mathrm{C}_{\text {out }}[\%]$ \\
\hline MG-R & 0.2333 & 11.12 & 16.6 & 23.9 & 43.98 \\
MG-C & 0.2471 & 10.88 & 24.6 & 42.2 & 71.54 \\
MG-Z & 0.2498 & 2.66 & 35.6 & 40.0 & 12.36 \\
\hline
\end{tabular}

\subsubsection{Combined Effect of ET and Porous Media Material Size}

To test the influence of the porous media material size, the CW units MG-R, FG-R and CO-R were modeled. These are planted with the same plant (common reed), but were filled with different type of porous media sizes, i.e., medium gravel, fine gravel, and cobbles, respectively (Akratos and Tsihrintzis 2007). The HRT used in the model was 8 days and the temperature $20{ }^{\circ} \mathrm{C}$. The results on effluent concentrations are presented in Table 5; BOD concentration profiles are presented in Fig. 6. The results show that the poorest effect of ET on BOD removal was recorded for the bed filled with medium gravel (MG-R), while the most significant one was for the bed filled with cobbles (CO-R), i.e., the coarser material.

\subsubsection{Combined Effect of ET and HRT}

To test the influence of hydraulic residence time (HRT) and ET, the MG-R CW unit was modeled for a temperature of $15^{\circ} \mathrm{C}$ and four typical values of HRT (i.e., 6, 8, 14 and 20 days). The values of $\lambda\left[\mathrm{d}^{-1}\right]$ for each HRT were computed using the empirical relations derived by Liolios et al. (2012). The model results are presented in Table 6 and Fig. 7. The results show that the highest effects of ET on BOD removal were recorded for the highest values of HRT, i.e., the lower inflow rate.

Table 5 Combined effect of ET and porous media material size on BOD effluent concentrations (Temperature: $20^{\circ} \mathrm{C}$; HRT: 8 days)

\begin{tabular}{lllllc}
\hline CW unit & $\lambda\left[\mathrm{d}^{-1}\right]$ & $\mathrm{ET}[\mathrm{mm} / \mathrm{d}]$ & $\mathrm{C}_{\text {out }}[\mathrm{mg} / \mathrm{L}]$ & $\mathrm{C}^{\mathrm{ET}}{ }_{\text {out }}[\mathrm{mg} / \mathrm{L}]$ & Increase of $\mathrm{C}_{\text {out }}[\%]$ \\
\hline MG-R & 0.2333 & 5.13 & 25.1 & 27.0 & 7.60 \\
FG-R & 0.2555 & 5.80 & 28.0 & 38.4 & 37.14 \\
CO-R & 0.2155 & 6.06 & 16.4 & 23.4 & 42.70 \\
\hline
\end{tabular}

Table 6 Combined effect of ET and HRT on BOD effluent concentrations (Temperature: $15^{\circ} \mathrm{C}$ )

\begin{tabular}{lllllc}
\hline HRT [d] & $\lambda\left[\mathrm{d}^{-1}\right]$ & $\mathrm{ET}[\mathrm{mm} / \mathrm{d}]$ & $\mathrm{C}_{\text {out }}[\mathrm{mg} / \mathrm{L}]$ & $\mathrm{C}^{\mathrm{ET}}$ out $[\mathrm{mg} / \mathrm{L}]$ & Increase of $\mathrm{C}_{\text {out }}[\%]$ \\
\hline 6 & 0.2207 & 6.51 & 66.00 & 71.60 & 8.48 \\
8 & 0.1912 & 6.24 & 56.70 & 91.71 & 63.75 \\
14 & 0.1366 & 6.32 & 43.80 & 81.50 & 86.07 \\
20 & 0.1062 & 6.05 & 24.40 & 53.01 & 117.21 \\
\hline
\end{tabular}


Table 7 Combined effect of ET and temperature on BOD effluent concentrations (HRT: 8 days)

\begin{tabular}{lllllc}
\hline $\mathrm{T}\left[{ }^{\circ} \mathrm{C}\right]$ & $\lambda\left[\mathrm{d}^{-1}\right]$ & $\mathrm{ET}[\mathrm{mm} / \mathrm{d}]$ & $\mathrm{C}_{\text {out }}[\mathrm{mg} / \mathrm{L}]$ & $\mathrm{C}^{\mathrm{ET}}{ }_{\text {out }}[\mathrm{mg} / \mathrm{L}]$ & Increase of $\mathrm{C}_{\text {out }}[\%]$ \\
\hline 8 & 0.1671 & 1.5 & 80.0 & 82.1 & 2.63 \\
15 & 0.2175 & 3.9 & 34.0 & 54.6 & 60.59 \\
20 & 0.2535 & 4.4 & 18.1 & 33.2 & 83.43 \\
\hline
\end{tabular}

\subsubsection{Combined Effect of ET and Temperature}

To test the influence of temperature and ET, the FG-R CW unit was modeled for HRT of 8 days and three typical values of temperature (i.e., 8,15 and $20^{\circ} \mathrm{C}$ ). The values of $\lambda\left[\mathrm{d}^{-1}\right]$ for each HRT were computed using the empirical relations derived by Liolios et al. (2012). The model results are presented in Table 7 and Fig. 8. As expected, the highest effects of ET on BOD removal were recorded for the highest temperature as a result of increased loss rates at high temperatures.

\section{Conclusions}

A numerical investigation for the effects of evapotranspiration and rainfall on the flow and BOD fate in horizontal subsurface flow constructed wetlands (HSF CW) has been presented. For this investigation, the Visual MODFLOW computer code was used in combination with experimental results from five pilot-scale $\mathrm{CW}$ units. Regarding rainfall effects, the numerical results show a slight reduction of the outlet concentration, implying dilution of wastewater and improvement of CW performance even though HRT reduces. The numerical results for the evapotranspiration effects show a rather significant in some cases increase of the outlet concentration, due to condensation of wastewater due to ET loss, even though HRT increases as a result of outflow reduction. This was the case of units where the incoming flow rate $Q_{i n}$ was greater than the subtracted $Q_{E T}$. In cases of $Q_{i n}<Q_{E T}$ (e.g., during some summer days in units FG-R and CO-R), the model predicted no outflow from the $\mathrm{CW}$ unit, and thus, a lowering of the water surface below the effluent water level control, something also observed during the experiments. It is concluded that ET has a significant role in operation of HSF CWs, under Mediterannean climate conditions. Finally, the influence of vegetation, porous media size, hydraulic residence time and temperarure, with and without ET, were also investigated.

Acknowledgments This research has been co-financed by the European Union (European Social Fund - ESF) and Greek National Funds through the Operational Program "Education and Lifelong Learning" of the National Strategic Reference Framework (NSRF) - Research Funding Program: Heracleitus II. Investing in knowledge society through the European Social Fund. An initial version of this paper was presented at the 8th International Conference of the EWRA in Porto, Portugal, June 26-29, 2013.

\section{References}

Akratos CS, Tsihrintzis VA (2007) Effect of temperature, HRT, vegetation and porous media on removal efficiency of pilot-scale horizontal subsurface flow constructed wetlands. Ecol Eng 29: $173-191$

Batu V (2006) Applied flow and solute transport modelling in aquifers. Taylor and Francis, Boca Raton Bear J (1979) Hydraulics of groundwater. McGraw - Hill, New York

Gikas GD, Tsihrintzis VA (2010) On-site treatment of domestic wastewater using a small-scale horizontal subsurface flow constructed wetlands. Water Sci Technol 62(3):603-614 
Harbaugh AW, McDonald MG (1996) 'User's documentation for MODFLOW-96, an update to the US geological survey modular finite-difference ground-water flow model U.S. geological survey open file report 96-485', Reston Virginia

Kadlec RH, Wallace S (2009) Treatment wetlands, 2nd edn. CRC Press, Boca Raton

Liolios KA, Moutsopoulos KN, Tsihrintzis VA (2012) Modeling of flow and BOD fate in horizontal subsurface flow constructed wetlands. Chem Eng J 200-202:681-693

Lott BR, Hunt RG (2001) Estimating evapotranspiration in natural and constructed wetlands. Wetlands 21(4): 614-628

Papaevangelou VA, Gikas GD, Tsihrintzis VA (2012a) Evaluation of evapotranspiration in small on-site HSF constructed wetlands. J Environ Sci Health A 47:766-785

Papaevangelou VA, Tsihrintzis VA, Gikas GD (2012b) Quantification of constructed wetland evapotranspiration using lysimeters. Fresenius Environ Bull 21(10a):3083-3092

Tsihrintzis VA, Gikas GD (2010) Constructed wetlands for wastewater and activated sludge treatment in North Greece: a review. Water Sci Technol 61(10):2653-2672

Vymazal J (2002) The use of sub-surface constructed wetlands for wastewater treatment in the Czech Republic: 10 years experience. Ecol Eng 18:633-646

Waterloo Hydrogeologic, Inc. (2006), Visual MODFLOW version 4.2 User's Manual

Zheng C (1990) MT3D: a modular three-dimensional transport model for simulation of advection, dispersion, and chemical reactions of contaminants in groundwater systems. S.S. Papadopoulos and Associates, Inc. Rockville, Maryland 20852, USA

Zheng C, Bennett GD (2002) Applied contaminant transport modelling, 2nd edn. Wiley, New York 